\title{
VITAMINAS HIDROSSOLÚVEIS (B6, B12 E C): UMA REVISÃO BIBLIOGRÁFICA
}

\author{
Hydrosolous vitamins (B6, B12 and C): a bibliographic review \\ Vitaminas hidrosolumbis (B6, B12 y C): una revisión bibliográfica
}

Otávio Cardoso Filho ${ }^{1 *}$, Isabela Barbosa Cruz $^{2}$, Amanda Rodrigues Santos ${ }^{1}$, Valéria Couto Quintão ${ }^{1}$, Lorena Roseli Rios Durães ${ }^{3}$, Renata Danielle Ribeiro ${ }^{4}$, Franciellen Morais Costa ${ }^{5}$, Lucas Barbosa $\mathrm{Cruz}^{6}$, Paulo Henrique Tolentino Moura ${ }^{1}$, Daniela Fernanda de Freitas ${ }^{1}$, Sônia Ribeiro Arrudas $^{1}$, Allan Crystia Pereira Sena da Cruz ${ }^{7}$, Patrícia Helena Costa Mendes ${ }^{1}$, Ludmilla Regina de Souza ${ }^{3}$.

\section{RESUMO}

Objetivo: O presente trabalho objetivou descrever a importância das vitaminas hidrossolúveis (B6, B12 e C) e verificar as consequências do excesso e da carência dessas vitaminas na dieta alimentar das pessoas. Material e Método: Trata-se de uma revisão da literatura científica dos periódicos disponíveis na Biblioteca Virtual em Saúde (BVS) e Scientific Electronic Library Online (SciELO) sobre o tema proposto. Resultado: A vitamina b12 é importante em várias fases do organismo, como no crescimento, desenvolvimento e maturação das células. A vitamina $C$ é de extrema importância para o desenvolvimento humano, pois ela é responsável pelo nosso sistema imune e pode ser facilmente encontrada em frutas cítricas. A vitamina B6, tem uma grande importância quanto aos processos de coenzimas. Desta forma, fica evidente a importância desse grupo de vitaminas para a dieta alimentar, tendo em vista que desempenha numerosos benefícios ao metabolismo. Conclusão: As vitaminas hidrossolúveis (B6, B12 e C) são substâncias que atuam na formação e manutenção de componentes essências ao funcionamento do organismo humano. Entretanto, o excesso e a carência dessas vitaminas podem acarretar prejuízos à saúde.

Palavras-chave: Vitaminas, Deficiência de Vitaminas, Vitaminas Hidrossolúveis.

\begin{abstract}
Objective: This study aimed to describe the importance of water soluble vitamins (B6, B12 and C) and to verify the consequences of the excess and the lack of vitamins of these vitamins in the diet of the people.Material and Method: This is a review of the scientific literature of the periodicals available in the Virtual Library in Health (VHL) and Scientific Electronic Library Online (SciELO) on the proposed theme. Result: Vitamin B12 is important in several phases of the body, for example in the growth, development and maturation of cells. Vitamin $\mathrm{C}$ is of utmost importance for human development because it is responsible for our immune system and can be easily found in citrus fruits and it plays an important role in our development. Vitamin B6, has a great importance in the processes of coenzymes. Conclusion: The water soluble vitamins (B6, B12 and C) are substances that act in the formation and maintenance of essential components to the functioning of the human organism. However, the excess and lack of these vitamins can lead to health damage.
\end{abstract}

Keywords: Vitamins, Avitaminoses, Water-Soluble Vitamins.

\footnotetext{
${ }^{1}$ Universidade Estadual de Montes Claros (UNIMONTES), Montes Claros - MG. * E mail:otaviobiol@hotmail.com

2 Faculdades Unidas do Norte de Minas (FUNORTE), Montes Claros- MG.

${ }^{3}$ Faculdades Promove - Belo Horizonte - MG.

${ }^{4}$ Faculdades Integradas Pitágoras (FIPMOC), Montes Claros - MG.

${ }^{5}$ Universidade Federal de Minas Gerais (ICA/UFMG), Montes Claros - MG.

${ }^{6}$ Faculdade de Saúde Ibituruna (FASI), Montes Claros - MG.

${ }^{7}$ Faculdades Santo Agostinho (FASA), Montes Claros - MG.
} 


\section{RESUMEN}

Objetivo: El objetivo de este trabajo fue describir la importancia de las vitaminas hidrosolubles (B6, B12 y C) y verificar las consecuencias del exceso y la carencia de las vitaminas de esas vitaminas en la dieta alimentaria de las personas. Material y Método: Se trata de una revisión de la literatura científica de los periódicos disponibles en la Biblioteca Virtual en Salud (BVS) y Scientific Electronic Library Online (SciELO) sobre el tema propuesto. Resultado: La vitamina b12 es importante en varias fases del organismo, por ejemplo, en el crecimiento, el desarrollo y la maduración de las células. La vitamina C es de extrema importancia para el desarrollo humano, ya que es responsable de nuestro sistema inmune y se puede encontrar fácilmente en frutas cítricas y desempeña un papel importante en nuestro desarrollo. La vitamina B6, tiene una gran importancia en cuanto a los procesos de coenzimas. De esta manera queda evidenciado la importancia de que esta vitamina sea ingerida en la dieta, pues desempeña muchos papeles de metabolismo. Conclusión: As hidrosolúveis vitamins (B6, B12 and C) são substância that atuam na formação e manutenção of components essências ao funcionalmento human organism. In the meantime, or excessively, these vitamins can cause prejuices to saude.

Palabras clave: Vitaminas, Avitaminoses, Vitaminas Hidrosolubles.

\section{INTRODUÇÃO}

As vitaminas são substâncias indispensáveis ao funcionamento do organismo que estão presentes em diversos alimentos em poucas quantidades (MENDONÇA JR et al., 2010).

A necessidade das vitaminas hidrossolúveis é aumentada nos processos de crescimento, gestação, lactação, condições de esforços intensos e na ocorrência de determinadas doenças. Podem ser classificadas em hidrossolúveis e lipossolúveis, segundo as características físico-químicas e propriedades fisiológicas (MONTEIRO, 2008)

As vitaminas hidrossolúveis (B6, B12 e C), objeto do presente estudo, de um modo geral possuem importante papel no desenvolvimento no organismo humano e por essa razão são encontradas em diversos alimentos (como peixe, carne, ovos queijo e leite) e são dissolvidas em água. $O$ armazenamento no organismo é uma das principais características dessas vitaminas. O seu mecanismo de eliminação é bem lento, nesse sentido podem ser armazenadas em grandes quantidades, não havendo necessidade de serem ingeridas diariamente. Os efeitos de sua absoluta carência na dieta podem também não serem manifestados fisiologicamente durante um longo período (PAIXAO e SATAMFORD, 2010).

A vitamina $\mathrm{C}$, por exemplo, é um micronutriente essencial à manutenção das funções fisiológicas normais do organismo, principalmente nas respostas imunes e funções cardíacas como na prevenção do câncer (MENDONÇA JR et al., 2010). Quanto à vitamina B12, age como coenzima ligada ao metabolismo dos aminoácidos e nas hemoglobinas do organismo humano (VANNUCCHI e CUNHA, 2016). A vitamina B6 desempenha papel no sistema nervoso central e participa do metabolismo dos lipídeos (KLAK, 2009).

Nesse sentido, o presente trabalho objetivou descrever a importância das vitaminas hidrossolúveis (B6, B12 e C) e verificar as consequências do excesso e da carência dessas vitaminas na dieta alimentar das pessoas.

\section{MATERIAL E MÉTODO}

Trata-se de uma revisão da literatura científica de periódicos nacionais e completos, com o intuito de analisar a importância das vitaminas hidrossolúveis (B6, B12 e C) e ainda buscar o que a literatura fornece sobre o excesso e carência dessas vitaminas.

A coleta de dados foi realizada através da busca online nas bases de dados Biblioteca Virtual em Saúde (BVS) e Scientific Electronic Library Online (SciELO ) sobre o tema proposto, durante o ano de 2016. 
Os critérios de inclusão foram: artigos publicados na íntegra, gratuitos, online e artigos publicados a partir do ano de 2008 até o presente momento. Foram excluídos os artigos que não discorriam acerca do tema proposto a escrita do presente trabalho.

\section{RESULTADOS E DISCUSSÃO}

\section{Vitamina B6 (piridoxina)}

A vitamina B6 segundo Mendonça (2010) desempenha o papel mais importante é o de coenzima no processo de transaminação para a síntese de aminoácidos. Por conseguinte, a piridoxina desempenha muitos papeis chave no metabolismo - em particular no metabolismo protéico. Além disso, Mendonça (2010) acredita-se que essa vitamina atue no transporte de alguns aminoácidos, como o triptofano através das membranas celulares, além da biossíntese de niacina.

Sabendo que a vitamina B6 desempenha diversos papeis metabólicos, com destaque na sua importância nos processos de coenzimas. Desta forma, torna-se importante o seu incremento na alimentação (MENDONÇA, 2010).

A vitamina B6 é necessária para o funcionamento adequado de mais de sessenta enzimas e essencial para a síntese normal do ácido nucléico e das proteínas. Participa da multiplicação de todas as células e da produção das hemácias e das células do sistema imunológico. Influencia o sistema nervoso através de seus efeitos sobre vários minerais e neurotransmissores cerebrais (HENDLER, 2010) (figura 1). A piridoxina é encontrada em maior proporção em alimentos de origem animal (carnes, de porco principalmente), leite e ovos. Entre os vegetais, assinala-se a batata inglesa, aveia, banana e gérmen de trigo (FRANCO, 2008).

Se esta imagem não for de propriedade dos autores, as

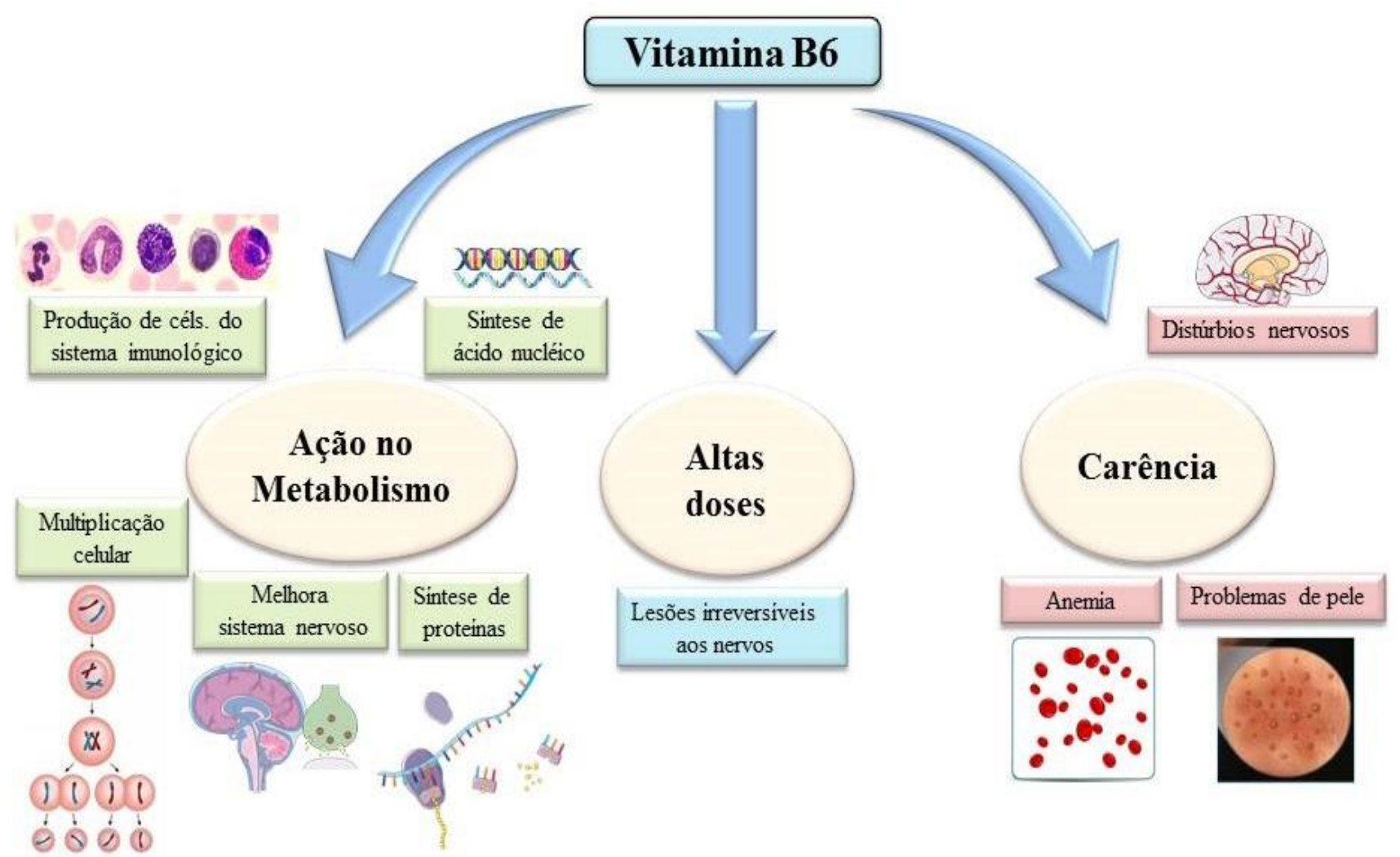

Figura 1: Principais ações da vitamina B6 no metabolismo e acometimentos em decorrência das altas doses e carência desse tipo de vitamina no organismo. Fonte: Dados da pesquisa, 2018. 
A deficiência severa pode provocar anemia, distúrbios nervosos e diversos problemas de pele (HENDLER, 2010) (Figura 1). Em muitos casos de deficiência piridoxina uma deficiência grave de vitaminas do complexo B acha-se associado. Na gravidez, a deficiência grave pode ocasionar deterioração da capacidade mental do recém-nascido. Todas as formas de piridoxina apresentam baixa toxicidade (FRANCO, 2008), mas segundo HENDLER (2010) em altas doses podem causar danos neurais graves e sérios efeitos colaterais. A ingestão de 2 a $6 \mathrm{~g}$ de piridoxina tomada diariamente por dois meses, por exemplo, causa lesões irreversíveis aos nervos levando a dormência, perda da coordenação motora (MENDONÇA, 2010) (Figura 1).

\section{Vitamina B12 (cobalamina)}

A vitamina $B_{12}$ foi descoberta através do estudo da anemia perniciosa, no homem. Em 1926, Murphy verificou que o consumo de fígado era eficaz no tratamento da anemia perniciosa, depois identificaram que era devido a um fator intrínseco produzido pelo estômago e extrínseco dietético. A complicada natureza da estrutura da vitamina $B_{12}$ foi estabelecida em 1956 (PAIVA, 2010).

Vale lembrar que este grupo prostético contém cobalto, com ligações de coordenação semelhantes às do ferro na molécula de hemoglobina. É provável que o átomo de cobalto funcione de modo idêntico ao do ferro para combinar-se reversivelmente com outras substâncias. (HENDLER, 2010).

Segundo Bertechini (2006), Esta vitamina difere das outras no processo de absorção no intestino delgado, porque há necessidade da produção de um fator intrínseco $(\mathrm{FI})$ na mucosa gástrica (região cárdica e fúndica), que se liga a vitamina $B_{12}$ na relação 1:1 (mol) sendo absorvida na região ileal.

Após absorção, a vitamina $\mathrm{B}_{12}$ é transportada ao fígado por uma globulina chamada transcobalamina II. Outra globulina, a transcobalamina I é responsável pelo transporte ao nível do plasma (BERTECHINI, 2006).

Ainda segundo Franco (2008) a vitamina b12 é importante em várias fases do organismo, por exemplo, no crescimento, desenvolvimento e maturação das células (Figura 2).

A vitamina B12 só existe em alimentos de origem animal. Exerce papel importante na formação do sangue, no crescimento e nos processos metabólicos, especialmente ligados a proteínas síntese de glicose a partir do ácido propiônico, hematopoese, participa da síntese de purinas e pirimidinas (Figura 2). A obtenção desse tipo de vitamina se da a partir da ingestão direta de alimentos ou ainda pode obtida da pré formação por meio da flora bacteriana em que os animais utilizam para sua obtenção, tendo em vista que tal vitamina não é encontrada nos vegetais (BERTECHINI, 2006).

É de fundamental importância que esta vitamina esteja presente na alimentação diárias dos adolescentes, para que este tenha um habito de vida saudável, e para que futuramente tenham uma boa qualidade de vida. (FRANCO, 2008).

Quanto a vitamina B12 à sua deficiência ocorre na produção de fator intrínseco, necessário para a absorção da cobalamina. Pode provocar anemia perniciosa, cujos sintomas são: alterações neurológicas, progressivas e mortais se não houver tratamento; fraqueza; convulsões e dano irreversível no tecido parietal gástrico (Figura 2). Interferindo diretamente na produção e desenvolvimento das hemácias (HENDLER, 2010).

Segundo, Bertechini, 2006 nas aves, há redução da síntese proteica, na fertilidade e peso dos ovos, perose, encurtamento do bico, etc.

É essencial para o funcionamento da célula, principalmente no trato gastrointestinal, medula óssea e tecido nervoso (HENDLER, 2010). A vitamina B12 tem suas maiores fontes nos alimentos de origem animal: carnes de vaca e de porco, miúdos (especialmente rim e fígado), peixes, laticínios, ovos (FRANCO, 2008). A deficiência pode provocar distúrbios nervosos e danos cerebrais, bem como uma forma de anemia 
(HENDLER, 2010). A vitamina B12 é bem tolerada; reações alérgicas têm sido relatadas após injeção intramuscular (FRANCO, 2008). Não há indícios de toxicidade em altas doses (HENDLER,2010)

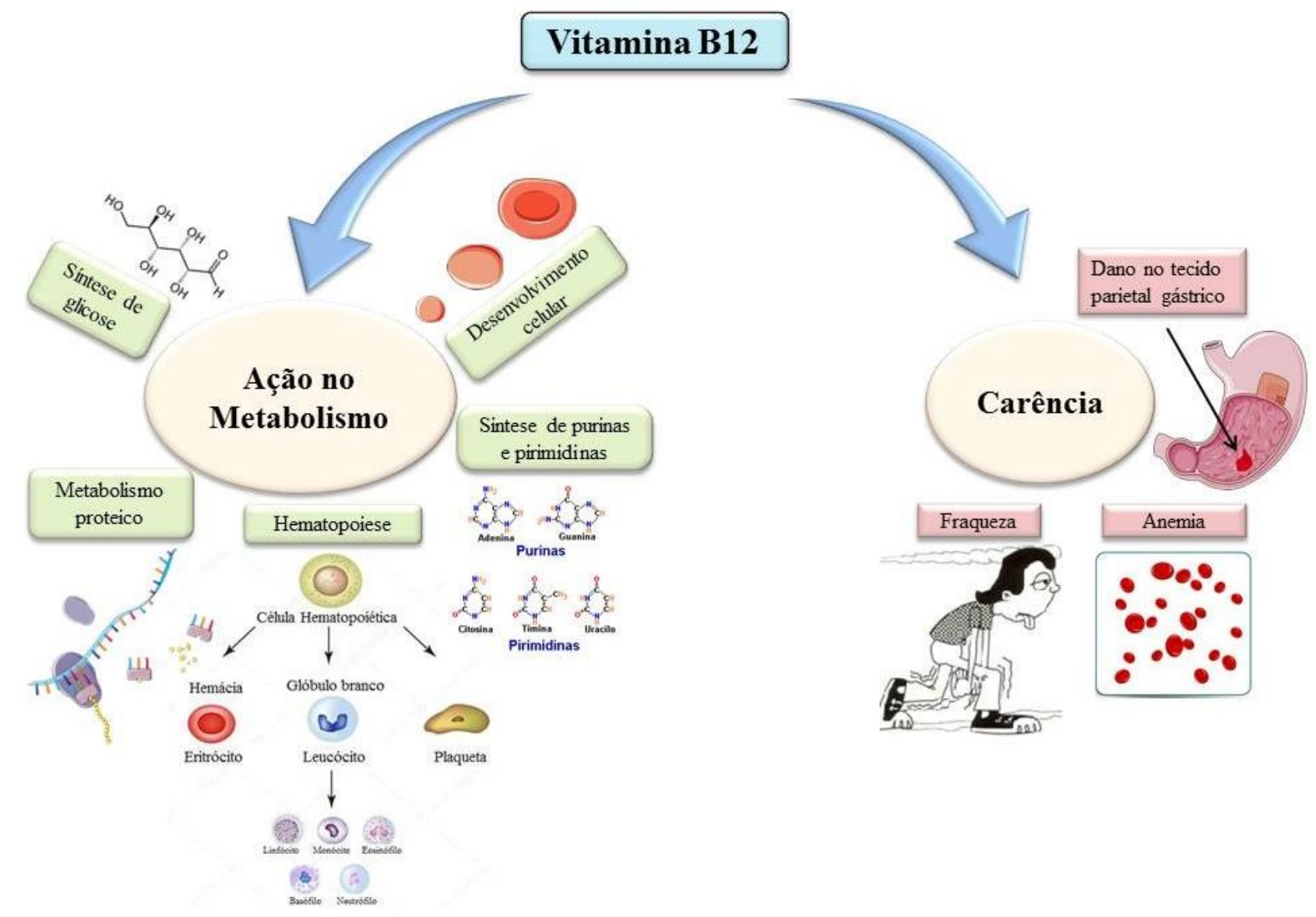

Figura 2: Principais ações da vitamina B12 no metabolismo e acometimentos em decorrência da carência desse tipo de vitamina no organismo. Fonte: Dados da pesquisa, 2018.

\section{Vitamina C (ácido ascórbico)}

A vitamina $\mathrm{C}$, também conhecida como ácido ascórbico é sintetizada pela maioria das plantas e por todos os mamíferos (exceto homem, primatas e porco da índia) a partir da glicose. As aves também sintetizam o acido ascórbico, salvo em condições de estresse, principalmente calórico, pois há um bloqueio no sistema enzimático envolvido na biossíntese dessa vitamina. Os suínos de uma maneira geral sintetizam toda vitamina que necessitam. Somente leitões até 6 semanas de idade necessitam suplementação na ração.(BERTICHINI, 2006)

A vitamina $C$ é de extrema importância para o desenvolvimento humano, pois ela é responsável pelo nosso sistema imune e pode ser facilmente encontrada em frutas cítricas e ela desempenha um importante papel no nosso desenvolvimento (DOMINGUES, 2011).

Ainda segundo o autor, na ausência de ácido ascórbico, o colágeno formado é defeituoso e fraco. Por conseguinte essa vitamina é essencial para o crescimento subcutâneo, da cartilagem do osso e dos dentes (DOMINGUES, 2011) (Figura 3).

Uma importante função é a hidroxilação de prolina e lisina em colágeno, permitindo a formação da estrutura helicoidal normal do composto. A reação também requer á-cetoglutarato e ferro ferroso. (BERTICHINI, 2006) 
A sua carência origina defeitos nas diversas funções como a fragilidade capilar, ossos fracos e lenta cicatrização de feridas, observada no escorbuto (HENDLER, 2010) (Figura 3).

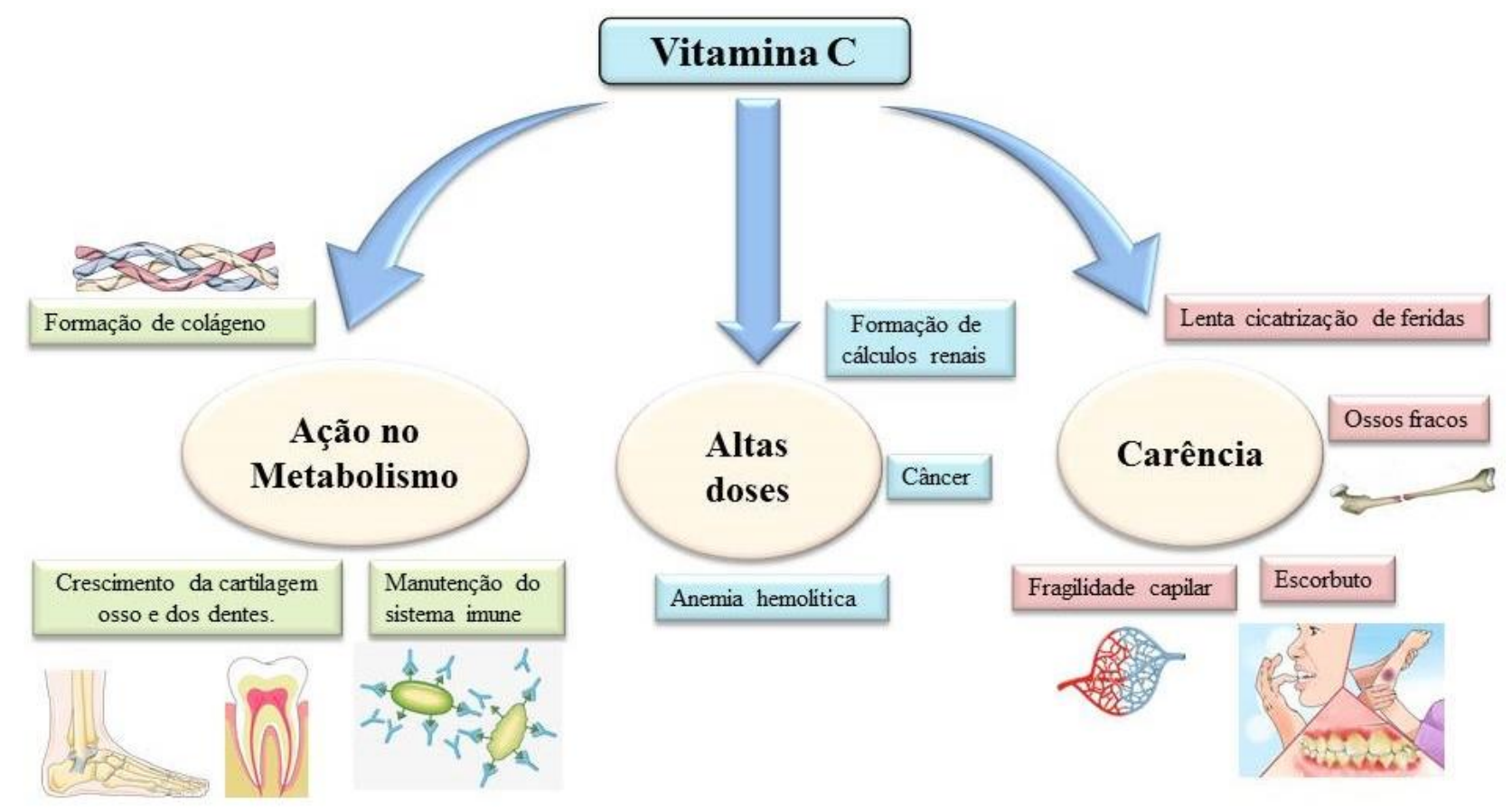

Figura 3: Principais ações da vitamina $C$ no metabolismo e acometimentos em decorrência das altas doses e carência desse tipo de vitamina no organismo. Fonte: Dados da pesquisa, 2018.

A deficiência de ácido ascórbico provoca escorbuto. Um dos efeitos mais importantes do escorbuto é a cicatrização deficiente das feridas. Essa deficiência de cicatrização decorre da incapacidade das células de depositar fibrilas de colágeno e cimento intercelular em consequência, a cicatrização de uma ferida pode exigir muitos meses, em lugar dos poucos dias normalmente necessários. A deficiência de ácido ascórbico determina a parada do crescimento ósseo (PAIVA, 2010) (Figura 3).

A toxicidade causada pelo excesso no consumo da vitamina $C$, provoca agravos fisiológicos graças a acometimentos como, formação de cálculos renais e crises de excesso de acido úrico levando a crises de gota, cefaleia, sensações de calor excessivo, diarreia, cólicas abdominais. A alta taxa de ingestão desse tipo de vitamina pode ser evidenciada com maior frequência em judeus, asiáticos e negros americanos, pois se trata de indivíduos com deficiência enzimática hereditária e a busca por suprir essa deficiência, provoca o alto consumo da vitamina $C$ e eleva a possibilidade de desenvolverem anemia hemolítica (HENDLER, 2010 e FRANCO, 2008). Além disso, outros acometimentos como simples resfriado e diversos tipos de câncer, são considerados como possíveis consequências do elevado consumo da vitamina mencionada (MONTEIRO, 2008) (Figura 3).

\section{CONCLUSÃO}

As vitaminas hidrossolúveis (B6, B12 e C) são substâncias que atuam na formação e manutenção de componentes essências ao funcionamento do organismo humano. Entretanto vale ressaltar que carência dessas vitaminas pode acarretar prejuízos a saúde, assim como as consequências da toxicidade decorrente das altas doses. $O$ estudo permitiu ainda verificar a carência de estudos que embasem a prática cotidiana dos profissionais de saúde sobre a importância das vitaminas hidrossolúveis (B6, B12 e C) para a nutrição 
saudável. Assim, recomenda-se outros estudos mais aprofundados sobre as vitaminas, uma vez que, essas substâncias são essenciais ao desenvolvimento e de funções biológicas.

\section{REFERÊNCIAS}

1. BERTECHINI AG. Nutrição de monogástricos. UFLA, 2006; 1(1) 301.

2. DOMINGUES G. Relação entre medicamentos e ganho de peso em indivíduos portadores de autismo e outras síndromes relacionadas. Nutrição Ativa. 2011; 17(2): 455-468.

3. FRANCO M. A importância da alimentação saudável. Revista nutrição, Campinas. 2008; 1(S): 235 e 236.

4. HENDLER SS; Vitaminas e saúde. Jornal de pediatria. Rio de Janeiro. 2010; 1(2): 34- 36.

5. KLACK K, CARVALHO JF. Vitamina K: metabolismo, fontes e interação com o anticoagulante varfarina. Revista Brasileira de Reumatologia. 2008; 46(6): 398-406.

6. MENDONÇA JÚNIOR FA, BRAGA AP, RODRIGUES APMS, SALES LEM. Vitaminas: uma abordagem prática de uso na alimentação de ruminantes. Revista Agropecuária Científica no Semi-Árido. 2010; 6(4):01-16.

7. MONTEIRO T. Carência de vitamina D: um problema de saúde pública não reconhecido e frequente no Grande Porto. Ac ta Pediátrica Portuguesa.2008, 40(2): 49-52.

8. PAIVA MR. A importância da alimentação saudável na infância e na adolescência. Revista Brasileira de Pediatria. 2010; 15(5): 520-523.

9. PAIXAO JÁ, STAMFORD TL. Vitaminas lipossolúveis em alimentos- uma abordagem analítica. Química Nova. 2010; 27(1): 96-105.

10. VANNUCCHI H, CUNHA SFC. Vitaminas do Complexo B: Tiamina, Riboflavina, Niacina, Piridoxina, Biotina e Ácido Pantotênico. Força-tarefa Alimentos Fortificados e Suplementos. 2016; 9 (1): 4-36. 